\title{
Abstracts of Symposium
}

on

\section{Biology of Cerebral Endothelium}

\author{
26-28 June, 1987 \\ Donald Gordon Center, Queen's University \\ Kingston, Canada
}

ORGANIZING COMMITTEE

Dr. S. Nag (Chairman)

Dr. D. Brunet

Dr. H. B. Dinsdale

Dr. L. R. Drewes (U.S.A.)

Dr. S. I. Harik (U.S.A.)

Dr. D. M. Robertson 


\section{Biology of Cerebral Endothelium An Overview}

An international symposium was held at Queens' University (Kingston, Ont.) as a satellite of the 12th International symposium on Cerebral Blood Flow and Metabolism. There were six sessions consisting of platform presentations and two keynote lectures: one given by Dr. Albert Gjedde on "Blood-Brain Barrier Transport: Past, Present and Future Directions; the other given by Dr. Henry B. Dinsdale on Blood-Brain Barrier: Clinical and Therapeutic Implications". An overview of the proceedings follows. The numbers in brackets refer to the numbered abstracts on the subsequent pages, commencing on page 336.

\section{Cerebral Endothelium - Structure, Properties and Cellular Interactions}

Several studies suggest that there is polarity of some endothelial properties such as surface charge since more anionic groups were observed on the luminal than abluminal plasma membrane of microvessel endothelium (2) and prostaglandin release since prostacyclin and $\mathrm{PGE}_{2}$ appeared to be released mainly from the basal surface of endothelium.(7) In addition, data was presented suggesting that endothelium expresses a polarity regarding the internalization of its cell surface membrane since CSF-borne native horseradish peroxidase and wheat germ agglutinin-HRP were not indocytosed at the abluminal face of endothelium while, when these tracers are blood-borne, they were endocytosed at the luminal face of cerebral endothelium and appeared within cytoplasmic organelles.(22)

A new area of study is the role of endothelium in immunological reactions. Data was presented which suggest that immune cells release factors which induce I-A molecules on endothelial cells which subsequently acquire the capacity to precent antigen.(8)

The hypothesis that astrocytes induce BBB characteristics in endothelial cells is supported by two additional studies. $(11,12)$ In the first study,(11) astrocytes transplanted into the anterior eye chamber or on the chorioallantoic membrane induced BBB properties in newly formed host-derived capillaries which became non-leaky to Evans-blue. In the second study,(12) weanling mice with a standard freeze-injury demonstrated gamma glutamyl transpeptidase (GGTP) only in endothelium of microvessels in contact with astrocytes supporting the concept that astrocytic contact was associated with GGTP induction in cerebral endothelium.

Studies demonstrate that cerebral endothelium resembles noncerebral endothelium in certain characteristics such as the composition of the surface glycoproteins,(1) the nature of the basement membrane glycosaminoglycans(9) and the localisation of $\mathrm{Ca}^{2+}$-ATPase.(27)

\section{Endothelium - Permeability in Normal and Pathological States}

Pinocytosis, and transcytosis by vesicles either singly or as part of a transendothelial channel are well recognized mecha- nisms for transport of protein and protein tracers in noncerebral endothelium. Despite the demonstration of this phenomenon in numerous pathological conditions, some neuroscientists remain skeptical that this process operates in cerebral endothelium. Several presentations emphasized the importance of pinocytosis in BBB breakdown in cold injury,(23) inflammation,(24) acute hypertension(27) and the BBB breakdown induced by bradykinin.(29)

Evidence was presented which suggested to the authors that the increased cerebrovascular permeability observed in response to intracarotid administration of hyperosmolar solutions was due to junctional opening.(38)

How dexamethasone reduces cerebral edema in brain tumors is an important question. Evidence was presented that dexamethasone treatment eliminated the bulk flow of plasma-derived edema fluid into the tumor and through the extracellular space of both tumor and the adjacent brain tissue.(28) Of interest was the finding that pretreatment of animals with indomethacin, trifluoperazine and imidazole reduced the BBB permeability to HRP induced by bradykinin.(29) The mechanism by which these drugs reduce permeability is unclear.

\section{Cerebral Endothelium - Biochemical Aspects}

Several papers dealt with glucose transport in cerebral endothelium in chronic hyperglycemia,(17) in vitro in presence of phorbol esters (16) and in wet-dog shakes induced by kainates.(15) The glucose transporter, previously demonstrated in rat and pig microvessels, was studied in human microvessels and found to be several fold higher in microvessels than the cerebral cortex.(14)

A number of studies related to choline uptake by cerebral endothelium. Data was presented indicating that endothelium is not the origin of vasoactive acetylcholine in major cerebral arteries and small pial vessels.(19) Evidence for the existence of high-affinity choline transport in cerebral endothelium was presented.(20) The unidirectional transport of a choline analog across the BBB and the capillary endothelium of extracranial vessels was demonstrated by positron emission tomography.(26)

The discovery that a Parkinson-like syndrome in humans is related to MPTP has led to numerous studies of MPTP neurotoxicity. Results of studies testing the suitability of a number of structural analogs of MPTP as substrates for monoamine oxidase was presented.(21)

\section{Studies of Vessels of Pia Mater, Choroid Plexus and Subfornical Organ}

A study demonstrated that in pial arterioles and venules endothelial denudation was not a prerequisite for platelet aggregation.(30) This contrasts the findings in large blood vessels in which platelet aggregates do not form unless the endothelium is denuded.

Since pial vessels can be observed through cranial windows 
they were used for studies of vascular reactivity to a number of pharmacological agents. Evidence was presented suggesting that endothelium plays an important role in the pial vessel response to sympathetic stimulation(31) and that there may be an endothelium-derived factor which affects calcium flux into vascular smooth muscle.(34)

Studies of permeability of pial vessels to fluorescent dextran in acute hypertension suggest that protection of pial vessels during hypercapnia is not mediated by direct effects of acidosis or vasodilatation, and is related to attenuation of increases in pial venous pressure.(33) The role of arginine vasopressin in regulation of cerebral circulation was presented.(36) Blood flow studies using microspheres demonstrated that vasoactive substances such as adenosine and sympathomimetics have different effects on blood flow to the choroid plexus and cerebrum.(39)
The hypothesis that the density of capillary networks varies directly with the level of functional activity among individual brain nuclei was investigated in the sub-fornical organ.(5)

\section{Methodology Related to Transport}

A number of papers dealt with methodology related to transport. Transport of large neutral amino acids was studied by means of two mathematical models.(18) The blood-to-brain transport of a variety of agents was studied by the indicator dilution technique and the brain uptake index technique.(35) A modification of the indicator dilution method with intravenous rather than intracarotid injection of isotopes was presented.(37) The advantages and drawbacks of these techniques was discussed.

Sukriti Nag Sami I. Harik 
Characterization of the Blood-brain Barrier: Glycoconjugate Receptors of 14 Lectins in Canine Brain, Cultured Endothelial Cells, and Blotted Membrane Proteins

\section{L.R. DREWES, M.I. FATEHI and D.Z. GERHART (Duluth, Minnesota)}

Surface membrane glycoproteins may play a role in the structure and function of the blood-brain barrier under normal and pathological conditions. ${ }^{1.2}$ The molecular composition of glycoconjugates of the brain endothelium may be probed with saccharide-specific lectins. In the present studies, the avidin-biotinylated peroxidase complex (ABC) method and 14 different lectins were used to detect lectin receptors of canine cerebral cortex and pituitary as well as of intact cells and electrophoretic blots of solubilized membrane proteins from cultures of the canine cerebral endothelium. When applied to frozen sections of canine cerebral cortex and pituitary and evaluated by light microscopy, these lectins produced distinct staining patterns as determined by their individual carbohydrate specificities. Major saccharide residues detected in the endothelia of these cerebral tissues include $\alpha$ - and $\beta$-galactose, $\alpha$-mannose and/or $\alpha$-glucose, and $\mathrm{N}$-acetylglucosamine. $\alpha$-Fucose and $\beta-\mathrm{N}$-acetylgalactosamine were not detected. No significant differences were noted between the staining of cortical and pituitary vessels for any of the lectins. However, some differences in lectin receptor distribution were observed between capillaries and arterioles and between microvessels of gray and white matter. Application to cells cultured from the canine cerebral endothelium gave staining results similar to those of microvessels in tissue. ${ }^{3}$ These characteristics of intact capillaries thus are retained in cultured cells and define fundamental properties of the blood-brain interface. Lectin binding characteristics were retained for a minimum of four cell passages. Visual comparison of these staining patterns to those obtained for electrophoretic blots of solubilized membrane proteins identified multiple glycoprotein receptors $(\mathrm{Mr}>$ $66,000)$ for individual lectins and illustrated the vast quantity and variety of surface carbohydrate residues and the complexity of the cerebral endothelial cell glycocalyx. This carbohydrate-rich layer, which extends into the capillary lumen, is an integral part of the cerebral endothelium. Such a layer may 1) facilitate intercellular contacts; 2) regulate endothelial cell-blood cell interactions; 3 ) provide restricted diffusion of metabolites near the cell surface; and 4) serve as a protective filtration barrier. The cerebral endothelial cell glycocalyx may, therefore, contribute to the unique function of the blood-brain barrier. 'Vorbrodt, et al., J. Histochem. Cytochem. 34: 251-261, 1986

${ }^{2} \mathrm{Nag}$, Lab. Invest. 52: 553-558, 1985

${ }^{3}$ Gerhart, et al., J. Histochem. Cytochem. 34: 641-648, 1986

2.

Localization of Anionic Sites on Luminal and Abluminal Aspects of Cerebral Endothelial Cells

\section{A.W. VORBRODT and D.H. DOBROGOWSKA (Staten Island, New} York)

Cationic colloidal gold (poly-L-lysine-gold complex, PLG) was synthesized and used as a cationic probe in accordance with principles described by Skutelsky and Roth (J. Histochem. Cytochem. 34: 693, 1986). The application of PLG to ultrathin sections of tissue samples embedded in hydrophilic resin Lowicryl $\mathrm{K} 4 \mathrm{M}$ enables one to demonstrate the distribution of anionic sites on both luminal and albluminal fronts of endothelial cells (EC) and also in adjacent structures like basement membrane (BM), the surface of smooth muscle cells, perivascular astrocytic processes and pericytes.

Brain capillaries, representing blood-brain barrier (BBB) type of micro-blood vessels (MBVs) show polar distribution of anionic sites evidenced by more intense labelling of luminal than albuminal plasma membrane (PM) of the EC. On the contrary, in venules, mostly abluminal PM and BM are labelled. In arterioles, both fronts of the EC are similarly labelled, whereas the PM of smooth muscle cells is almost unlabelled.

Relatively intense labelling of the BM in brain MBVs indicates that this structure constitutes a negatively charged screen interposed between endothelium and adjacent interstitial tissue.

For comparison, non-BBB type of MBVs from choroid plexus, skeletal muscle and liver sinusoids are also examined. Capillaries of skeletal muscle are characterized by uniform labelling of both aspects of the $\mathrm{EC}$, whereas fenestrated endothelia of the choroid plexus and liver sinusoids are characterized by more complex and less regular labelling.

In spite of some technical difficulties, the application of cationic colloidal gold to tissue samples embedded in hydrophilic media seems to be a new efficient tool in the study of cellular anionic constituents.

Supported in part by NINCDS grant No. NS-17271-06.

3.

Cerebral Microvessel Endothelial Cell Cultures as a Model for Studies of Gap Junction Neogenesis

R.R. SHIVERS, F.E. ARTHUR and P.D. BOWMAN (London, Canada; Ann Arbor, Michigan)

The synthesis, insertion into the plasma membrane, and final assembly of intramembrane particles into discrete intercellular gap junctions are processes poorly understood and essentially undocumented morphologically. Lack of a suitable model system for investigation of gap junction formation is the major reason why the life history of this important device for intercellular communication has not been fully characterized. Monolayer cultures of bovine brain endothelial cells are proposed as ideal models for study of gap junction genesis in which the temporally-expressed structural features of the synthesis and assembly steps of this process can be precisely determined. Brain microvessel endothelial cells (5th passage) grown on ECM-coated substrates (Cedar Lane Labs., Hornby, Ont.) in medium composed of $50 \%$ brain astrocyteconditioned medium and 50\% $\alpha$-MEM (Gibco, Grand Island, N.Y.) develop unusually large and numerous gapjunction-like intramembrane particle aggregates (plaques) within one week after plating. Control cultures grown on either ECM-coated coverslips or fibronectin-coated coverslips (Bowman, et al., 1981; Thermonox, Lux Scientific Corp., Newbury, Ca., $24 \times 30 \mathrm{~mm}$ ) in $\alpha$-MEM failed to display any discrete particle aggregates that could be classified as gap junction-like. The gap junction-like particle aggregates frequently displayed evidence of formation (Shivers and Bowman, 1985) by addition of particles disposed as "streaming" arrays at the perimeter of the aggregates. Careful examination of platinum replicas of cultures of endothelial cells from one day post-plating to confluency revealed a sequence of images of particle aggregates consistent with the notion that formation of these unique structures proceeds by progressive packing of particles from the randomly-distributed intramembrane particle population. Since this process appears to be amplified and accelerated in microvessel endothelial cultures grown under the conditions described here, the individual phases of this complex phenomenon can be systematically and easily distinguished and analyzed. (Support: N.S.E.R.C.).

4.

Contractile Elements in Cerebral Veins Without a Smooth Muscle Layer

\section{R. KLEINERT and L.M. AUER (Graz, Austria)}

Previous work has shown that cerebral veins exhibit contractile responses especially to norepinephrine; while this effect has been observed under various physiological and pathophysiological conditions, 
the morphological basis for this venoconstrictor effect has not been well understood.

In a series of six cats and human brain tissue specimens, histological investigations were performed on formalin-fixed and paraffin-embedded coronal sections of the cat brains. For immunohistochemical investigation the ABC-method was used and antibodies to actin and myosin were prepared from chicken gizzard (by H. Denk, et al.).

Results: Positive immunostaining for actin and myosin was found in the endothelial cells of pial, intracortical and white matter, postcapillary venules and small as well as large collecting veins. In the latter also in smooth muscle cells of the media. Both reactions showed the characteristic morphological pattern: Actin staining was concentrated in the perinuclear area of endothelial cells, Myosin staining was more intense close to the inner surface of the cellular membranes. Similar observations were made in endothelial cells in small veins of the human specimens from cerebral cortical and subcortical tissue. These data indicate that endothelial cell and intermediately surrounding endothelial cells of cerebral veins contain a contractile high amount as basis of contractility previously described to occur under physiological and pathomorphological conditions

5.

Heterogeneity of the Capillary Endothelium Within One Cerebral Nucleus, the Subfornical Organ

P.M. GROSS and N.M. SPOSITO (Kingston, Ontario; SUNY-Stony Brook, New York)

Craigie (1920) first postulated that the density of capillary networks varied directly with the level of functional activity among individual brain nuclei. Can this hypothesis apply also to the fine structure of the cerebral capillary endothelium? We examined the possibility by an electron microscopic analysis of capillaries in a small forebrain nucleus of rats, the subfornical organ (SFO). The SFO can be differentiated topographically into seven regions of nonuniform cytoarchitecture, neural afferents and efferents, immunoreactivity to several peptides and amines, and hetrogeneous capillary density. These facts indicate compartmentation of function within the organ.

Three distinct kinds of capillary endothelial cells were present: I. continuous endothelium with few pinocytotic vesicles, nofenestrations, and closely apposed basal laminae (i.e., "blood-brain barrier" endothelium) was found in the rostroventral stalk (capillary density = $186 / \mathrm{mm}^{2}$ ); II. continuous endothelium with high numbers of vesicles was present in six regions but predominantly between the rostral stalk and central region (capillary density $=294 / \mathrm{mm}^{2}$ ); and III. discontinuous, highly fenestrated endothelium with large numbers of vesicles, thin walls, and wide pericapillary labyrinths was located mostly in the ventromedial zones of the central and caudal regions where capillary density was highest $\left(551 / \mathrm{mm}^{2}\right)$. Rapid blood-brain exchange may occur primarily in this part of the SFO. The study reveals differentiation of endothelial ultrastructure and capillary density that may correspond spatially with different neurohumoral functions within this one cerebral nucleus.

Craigie, E.H. (1920) J. Comp. Neurol. 31: 429-464.

6.

Blood-brain Barrier Defect in Human Peritumoral Brain Correlates with Density of Invading Tumour Cells

P.A. STEWART, C.L. FARRELL and R.F. DEL MAESTRO (Toronto and London, Ontario)

The form and function of blood vessels is determined by the cells that constitute their microenvironment. Brain tissue around tumours contains varying numbers of tumour cells that could influence local capillaries to lose their blood-brain barrier (BBB), as they do in the tumour itself. Microvascular permeability cannot be measured directly in the human but can be inferred from a knowledge of vessel ultrastructure. The objective of this study was to examine BBB-associated vascular ultrastructure in human peritumoural brain for evidence of barrier compromise and, further, to correlate barrier features with the cellular components of the vessel microenvironment. Light microscopic examination showed that brain samples selected from beyond the visible edge of the tumour range from essentially normal to grossly infiltrated with tumour cells. Although a percentage of the vessels were structurally normal, microvessels as a group have elongated junctional clefts (unfused regions) and an increase in the density of endothelial vesicles. Furthermore, the cleft index (percentage of the junctional profile that is unfused) varies directly with the local cell density. A subpopulation of vessels enveloped by a layer of tumour cells were grossly abnormal. However, vessels that were not immediately invested by tumour cells also show some abnormalities. We conclude that tumour cells infiltrating peritumoural brain cause blood vessels to take on some of the structural characteristics of leaky vessels. Since direct contact is not required, and since the degree of abnormality correlates with the number of tumour cells in the environment, we suggest that this inductive influence is exerted over a distance and is dependent on the concentration of the inducing factor(s).

\section{7.}

Cerebral Endothelia Produce Prostaglandins $I_{2}$ and $E_{2}$ In Vitro and Release Them Predominantly from Their Basal Surfaces

\section{S.A. MOORE, A.A. SPECTOR and M.N. HART (lowa City, lowa)}

A line of cultured endothelia derived from murine cerebral microvessels and characterized by a monolayer growth pattern, thrombomodulin activity, and Griffonia simplicifolia lectin binding produces predominantly prostacyclin $\left(\mathrm{PGI}_{2}\right)$ and prostaglandin $\mathrm{E}_{2}\left(\mathrm{PGE}_{2}\right)$. Cells in passages $8^{2}$ and 24 were exposed to arachidonate $(20: 4)$ in concentrations up to $15 \mu \mathrm{M}$ or stimulated by 2 to $5 \mu \mathrm{M}$ calcium ionophore (A23187). Metabolites of 20:4 were then assayed by radioimmunoassay or by reverse phase high performance liquid chromatography. With exposure to trace amounts of $20: 4$ the endothelia produce predominantly $\mathrm{PGI}_{2}$ and $P G E_{2}$, in a ratio up to 3:1, respectively. This ratio, however, reverses when concentrations of $20: 4$ greater than $3 \mu \mathrm{M}$ are present or when cells are stimulated by $\mathrm{A} 23187$. Ratios of $\mathrm{PGI}_{2}: \mathrm{PGE}_{2}$ do not change appreciably with passage number or with time of exposure to 20:4. Studies of prostaglandin (PG) formation by these endothelia grown on micropore filters in a chemotactic chamber show PG release from both apical and basal surfaces during incubations with $7.5 \mu \mathrm{M} 20: 4$ or stimulation by $2 \mu \mathrm{M}$ A23187. The data, however, strongly suggest that both $\mathrm{PGI}_{2}$ and $\mathrm{PGE}_{2}$ are predominantly released from the endothelial basal surface. The ratio of basally to apically released PG has been measured as high as 10:1. Primary production of $\mathrm{PGl}_{2}$ by any microvesselderived endothelia has not been previously reported. The polarity of PG release suggests that eicosanoid production in cerebral endothelia is directed primarily at neighboring cells in the vessel wall or the brain parenchyma rather than at blood cells passing through the microvessel lumen.

US PHS-NIH \#1 K08 NS01096-1 and NIH \#HL14230.

\section{8.}

Cerebral Vascular Endothelial Cells and Myelin Basic Protein-Immune T Cells Interactions

R.M. McCARRON, M. SPATZ and D.E. McFARLIN (Bethesda, Maryland)

Several neurological disorders are characterized pathologically by cerebral infiltration of immune cells. The migration of lymphocytes across the blood-brain barrier (BBB) into the central nervous system 
implicates the cerebral capillary endothelial cell (EC), which is a principal component of the BBB, in the pathogenesis of such disorders.

Lymph node cells (LNC) from SJL mice immunized with guinea pig myelin in basic protein (BP) proliferate in vitro to the same antigen and transfer experimental allergic encephalomyelitis (EAE) to syngeneic recipients. The depletion of macrophages-monocytes by adherence to plastic and Sephadex G-10 elution abolishes the proliferative response of immune LNC to BP ( ${ }^{3} \mathrm{H}$-thymidine incorporation). This response can be reconstituted in an I-A-dependent manner by the addition of either exogenous macrophages or EC (Factor VIII-and I-A-positive) freshly isolated from syngeneic mice with adoptively transferred acute EAE. Reconstitution by EC from mice with EAE can be blocked by pretreatment of $E C$ with syngeneic anti-1-A antisera and complement. On the other hand, freshly isolated EC from normal syngeneic mice do not restore responsiveness. These cells are I-A negative but can be induced to express I-A molecules and present antigen by culture with murine recombinant immune gamma-interferon (IFN) or supernatants from a variety of immune cell cultures. Induction of I-A by all these factors is blocked by pretreatment with anti-IFN antibody.

These results are consistent with the hypothesis that immune cells release factors which induce I-A molecules on $\mathrm{EC}$ which subsequently acquire the capacity to present antigen. These findings indicate that $\mathrm{EC}$ may play a role in the pathogenesis of inflammatory neurological disorders.

\section{9.}

Glycosaminoglycans in Basement Membranes of Blood-brain Barrier Microvessels

\section{J. SCHMIDLEY, P. BLUE and M.J. MITCHELL (Cleveland, Ohio)}

The basement membrane (BM) of brain microvessels (MV) is unique among vascular $\mathrm{BM}$ because it does not stain discretely with ruthenium red $(R R)$, a cationic ultrastructural probe for the glycosaminoglycan (GAG) component of proteoglycans (PG). Despite this lack of ultrastructural cytochemical evidence for GAG in brain MV BM, the core protein of a heparan sulfate (HS) PG has been detected in brain MV BM by immunoperoxidase staining. To resolve this apparent paradox the presence of a PG core protein but absence of cytochemical evidence of a GAG component - we undertook direct analysis of the GAG content of brain MV BMs.

Microvessels were isolated from pig cerebral cortex (Harik, et al., $J$ $C B F$ Metab, 1985), and basement membranes freed from cellular elements (Carlson, et al., J Ultrastruct Res, 1978) by previously described techniques. Following digestion with papain and Pronase, the GAGs were precipitated with cetyl pyridinium chloride and ethanol. The resulting $\mathrm{BM}$ extract contained uronic acid, and after electrophoresis on Super Sepraphore in $\mathrm{Ca}^{++}-$acetate buffer revealed two bands: One co-migrated with HS standard, the other with chondroitin sulfate $A$ and $\mathrm{C}(\mathrm{CSA}+\mathrm{C})$. The first was completely eliminated by nitrous acid (NA) and heparitinase (Heptase), but not by hyaluronidase (Hyase) or chondroitinase $\mathrm{ABC}(\mathrm{CABC})$ and was therefore confirmed as $\mathrm{HS}$; the other band was eliminated by $\mathrm{CABC}$ but not by Hyase. Heptase, or NA.

The findings suggest that $\mathrm{BM}$ of brain $\mathrm{MV}$, like other vascular $\mathrm{BM}$, contains the GAGs HS and CSA $+C$. The failure of staining with $R R$ is probably a result of unique structural features of this $B M$, rather than an absence of GAG.

10.

Peroxidase Cytochemical Approaches Reveal the Blood Vessels of the CNS and of Intracerebral Allografts

R.D. BROADWELL, H.M. CHARLTON, B.J. BALIN and M. SALOMAN (Baltimore, Maryland)
Blood vessels of the fetal, neonatal, and adult primate and subprimate CNS and of solid CNS and non-neural allografts placed intracerebrally in an adult host are visualized by applying peroxidase cytochemistry in three ways. Native HRP is injected systemically just prior to perfusionfixation of the brain or is delivered into the aorta subsequent to perfusionfixation. The third approach utilizes brains from animals not receiving exogenous HRP; these brains are fixed by immersion and are incubated for endogenous peroxidase activity in red cells retained within the vessels. Cerebral vessels are outlined with blood-borne peroxidase when TMB as opposed to DAB is used as the chromagen; vessels of the circumventricular organs are not discernable due to the dense concentration of reaction product, a consequence of blood-borne HRP that has exited fenestrated capillaries. Ultra-structurally, reaction product coats the luminal surface of the cerebral endothelia and/or is sequestered in endocytic organelles and dense bodies within the endothelial cells. HRP infused into the aorta of fixed animals likewise obscures the circumventricular organs but fills the lumen of non-fenestrated vessels when incubated in DAB or TMB solutions; the cytoplasm of all endothelia and that of cells and processes in circumventricular organs are inundated with reaction product which suggests that the normally impermeable plasmalemma becomes permeable to protein in the fixed brain. Endogenous HRP activity of red cells outlines the blood vessels in the cerebral gray and white matter and all circumventricular organs. The three approaches applied to transplanted tissues demonstrate that the vascularization of day $16-19 \mathrm{fetal} / I$ day neonatal CNS grafts is not well-defined prior to seven days following intracerebral placement; conversely, the vascularization of non-neural grafts (anterior pituitary gland) is prominent prior to three days. This difference may reflect the inherent low vascularity of brain versus that of pituitary tissue. Donor CNS allografts contain blood vessels that are not leaky to blood-borne HRP and, therefore, contribute to the formation of a blood-brain barrier. Pituitary grafts exhibit fenestrated blood vessels that permit bloodborne HRP to enter the graft and surrounding host parenchyma. Blood vessels indigenous to allografts are retained and establish continuity with cerebral vessels of the host. The peroxidase cytochemical approaches for visualizing CNS blood vessels have potential application to studies of stroke, trauma, and neoplasia.

11.

Astrocytes Transplanted into the Anterior Eye Chamber or on the Chorioallantoic Membrane Induce Blood-brain-barrier Properties in Newly Formed Host-derived Capillaries

\section{R.C. JANZER and M.C. RAFF (Zurich, Switzerland; London, England)}

A competent blood-brain-barrier can be induced in non-neural endothelial cells by embryonic brain tissue (Stewart and Wiley, 1981). In order to elucidate the cellular and molecular mechanisms of this effect, we purified GFAP + , A2B5- astrocytes and injected them as a suspension into the anterior eye chamber of syngeneic adult rats. Within 48 hours the aggregated cells became vascularized. Perfusion with the tracer Evans-blue (EB) after various intervals showed that after 14 days the newly formed vessels were not leaky for the EB-albumincomplex. Immunohistochemistry showed only a very low amount of extravasal endogeneous albumin. If meningeal cells, 3T3-cells or human glioma cells were used as controls, the newly formed vessels were leaky to the EB-albumin-complex and albumin was present in high amounts in the interstitial space.

To exclude the unlikely possibility that the neovascularization was due to selective outgrowth of distant retinal vessels or to contamination with brain-derived endothelial cells of the primary inoculum, purified astrocytes, grown on filters were implanted on the chorioallantoic membrane of six days old chick embryos. Perfusion with EB and albumin-immunohistochemistry showed non-leaky vessels after 11 days of incubation. If fetal rat fibroblasts were used, the newly grown vessels were leaky. The host-origin of the vessels was demonstrated by 
using a species-specific anti-chick-antibody.

These results show that astrocytes induce endothelial cells to become non-leaky for albumin and therefore provide evidence that astrocytes induce endothelial cells to express blood-brain-barrier properties.

12.

Induction of Gamma Glutamyl Transpeptidase in Cerebral Endothelium: The role of the Astrocyte in vivo

\section{P.A. CANCILLA, J. BREADY, K. MAXWELL and J. BERLINER (Los Angeles, California)}

Gamma glutamyl transpeptidase (ggtp) is normally present in cerebral and retinal endothelium but not in endothelium of vessels in other organs. In vitro studies utilizing lines of mouse cerebral endothelium have shown that astrocytes or astrocyte-conditioned media are capable of inducing the enzyme in the endothelium. The present studies were done to determine whether or not a similar relationship exists in vivo. Weanling mice received a standard freeze-injury to the brain and were examined 5-8, 10, 12, 14, 16, 20 and 24 days later. The brain was fixed by formalin perfusion and individual paraffin embedded sections of the lesion and adjacent brain were prepared with an enzyme histochemical method for ggtp and an immunocy tochemical method for glial fibrillary acidic protein (gfap). Vessels $30 \mu$ in diameter or less were examined for endothelium staining for ggtp or contact with astrocytes containing gfap. Gfap stained astrocytes were demonstrable in contact with $30-40 \%$ of microvessels in the lesion from day 5-8 and increased to 70 or $100 \%$ of microvessels on day 10-24. Ggtp appeared two days after gfap and was generally demonstrable only in microvessels in contact with astrocytes expressing gfap. Serial sections demonstrated vessels in which ggtp and gfap were present in one segment and absence of gfap was associated with no ggtp in a contiguous vascular segment. The results support the concept that astrocytic contact is associated with ggtp induction in cerebral endothelium in regenerating microvessels. (NIH Grant \#NS19279)

13.

\section{Endothelial Cell Volume Regulation: In-Vitro Studies}

\section{O. KEMPSKI and M. SPATZ (Bethesda, Maryland)}

Cerebral capillary endothelial cells constitute the morphological structure affording the intense fluid and substrate exchange between the vascular system and the cerebral tissue. The regulation of endothelial cell volume is an important prerequisite for a stable microcirculation, and capillary function. We have, therefore, examined the volume regulatory capacity of cultured cerebromicrovascular endothelium (Spatz, et al., 1980) after hypotonic swelling. Cell volume of suspended cells was analyzed by flow cytometry using an advanced COULTER technique with hydrodynamic focussing. After reduction of the extracellular (e.c.) osmolality from 300 to $150 \mathrm{mosm} / 1$, endothelial cell volume increased within seconds to $160 \%$ of normal. Subsequently, cell volume normalized completely within one hour - although the e.c. osmolality was maintained low. Volume regulation was achieved by release of intracellular (i.c.) $\mathrm{K}^{+}$and amino acids. Concentrations of eight amino acids were measured by HPLC using precolumn derivatization with OP'T. Amino acid release was increased already after three min. as compared to normotonic exposure. The amino acids found in the incubation medium after $30 \mathrm{~min}$. of hypotonicity accounted for approximately $30 \mathrm{mM}$ of i.c. solutes. The release of taurine, glutamate, aspartate and threonine was increased 4-5 times over the control level. Glial cells which were similarly analyzed for comparison, also regulated cell volume but did not release glutamate or aspartate (both are putative neurotransmitters).
The vigorous volume regulating capacity of endothelium is consistent with the required high biological priority for a stable endothelial cell volume needed for proper function of cerebral capillaries as the main constituents of blood brain barrier.

14.

The Glucose Transporter of the Human Blood-brain Barrier

R. KALARIA, S. GRAVINA, J, SCHMIDLEY, L. OLSSON and S. HARIK (Cleveland, Ohio; Coppenhagen, Denmark)

We recently used cytochalasin $\mathbf{B}$ as a ligand for the identification and characterization of the glucose transporter in rat and pig cerebral microvessels and synaptosomes. We now extend our studies to microvessels and synaptosomes of the human cerebral cortex. and provide immunohistochemical localization of the glucose transporter in human brain. Specific $\left[{ }^{3} \mathrm{H}\right]$ cytochalasin B binding to tissues was estimated by subtracting nonspecific binding in the presence of D-glucose from total binding in the presence of $\mathrm{L}$-glucose. $\mathrm{D}$-glucose-displaceable $\left[{ }^{3} \mathrm{H}\right] c y$ tochalasin $\mathrm{B}$ binding to human brain microvessels and synaptosomes was saturable. Scatchard analysis revealed linear plots indicating a single class of noninteracting binding sites. Maximal binding (Bmax) for human brain microvessels and synaptosomes was $41.9 \pm$ 6.5 and $7.0 \pm 0.3 \mathrm{pmol} / \mathrm{mg}$ of tissue protein, respectively. The dissociation constant of binding $(\mathrm{Kd})$ to both tissues was similar at $0.3-0.5 \mu \mathrm{M}$. Irreversible D-glucose-displaceable cytochalasin B binding after UV irradiation, followed by SDS-PAGE enabled us to estimate the molecular weight of the glucose transporter in these preparations.

To ascertain the marked difference in the Bmax between brain capillaries and surrounding neuropil, we performed immunohistochemical studies of the human cerebral cortex. Monoclonal antibodies (IgM) to human erythrocyte glucose transporters interacted specifically with cerebral capillaries, with only minimal staining of the neuropil. The results of the immunohistochemical stains corroborate our binding studies. Studies are in progress to localize the glucose transporter moiety in brain microvessels at the ultrastructural level. These studies will allow the exact subcellular localization of the glucose transporter at the human blood-brain barrier.

15.

Modification to BBB Glucose Transport Characteristics in Rats Given Kainate

J. CREMER, M. SEVILLE and V.J. CUNNINGHAM (Carshalton, Surrey, U.K.)

During the period of wet-dog shakes induced by kainate, CMRG is stimulated several-fold in hippocampus, entorhinal cortex and amygdala, although there is no comparable increase in CBF. A short term 2-DOG technique (ref) has been used to examine the permeability of the bloodbrain barrier to glucose in these regions. It was observed that the proportional increases in glucose influx were greater than those in CMRG, particularly in the entorhinal cortex. A comparison of observed influx rates with measured capillary plasma $(\bar{c})$ and tissue $\left(C_{T}\right)$ glucose concentrations and the assumption of symmetrical transport, indicated that the maximal glucose transport capacity $\left(\mathrm{T}_{\text {max }}\right)$ increased while the apparent $K_{1}$ decreased. These results do not necessarily imply that the transport protein has a higher affinity for glucose but can also be explained by altered membrane fluidity or a lack of symmetry in the transport system. 
Parameters measured or estimated

\begin{tabular}{|c|c|c|c|c|c|}
\hline$\overline{\mathbf{c}}$ & Influx & $\mathrm{C}_{\mathrm{T}}$ & CMRG & $\mathbf{K}_{\mathrm{t}}$ & $\mathrm{T}_{\max }$ \\
\hline \multicolumn{6}{|c|}{ Entorhinal cortex } \\
\hline 12.7 & 3.71 & 3.39 & 1.37 & 3.43 & 4.71 \\
\hline 14.8 & 5.12 & 4.33 & 1.55 & 3.25 & 6.24 \\
\hline 11.4 & 7.15 & 3.77 & 1.69 & 2.06 & 8.44 \\
\hline \multicolumn{6}{|c|}{ Hippocampus } \\
\hline 12.2 & 2.71 & 2.10 & 1.49 & 4.10 & 3.62 \\
\hline 14.4 & 3.35 & 2.68 & 1.57 & 3.62 & 4.19 \\
\hline 11.0 & 3.61 & 2.15 & 1.69 & 3.01 & 4.60 \\
\hline
\end{tabular}

Data available from individual rats given kainate intravenously (12 $\left.\mathrm{mg} \cdot \mathrm{kg}^{-1}\right)$. Concentrations are given as $\mathrm{mM}$ and rates as $\mu \mathrm{mol} \cdot \mathrm{g}^{-1} \cdot \mathrm{min}^{-1}$.

Reference - Hargreaves, R.J., Planas, A.M. Cremer, J.E. and Cunningham, V.J. Studies on the relationship between Cerebral Glucose Transport and Phosphorylation using 2-deoxyglucose. J. Cereb. Blood Flow Metab., in press.

16.

Stimulation of Glucose Uptake by Brain Endothelial Cells in Response to Phorbol Ester

\section{L.R. DREWES, M.A. BRODERIUS, D.Z. GERHART (Duluth, Minnesota)}

A description of endothelial cell (EC) metabolism and its regulation is important in understanding the response of the cerebral microvasculature to biochemical and physiological stimuli. In this study brain EC were cultured from canine and human (autopsy) cerebral microvessels. A comparison of these cultures revealed species-specific morphological, biochemical, and growth characteristics. The EC were characterized by analyses of Factor VIII and angiotensin converting enzyme activity, lectin binding characteristics, growth rates, response to heparin and different growth substrates, and ultrastructure. Glucose uptake into cultured brain EC was determined in the absence and presence of the tumour-promoting agent, 12-O-tetradecanoylphorbol-13-acetate(TPA). TPA is an activator of protein kinase $\mathrm{C}$, which modulates several cellular processes including stimulation of hexose transport, hormone release, and regulation of the cell cycle and receptors. Monolayers of EC, maintained in culture for up to four passages, were treated with TPA (100ng/ml, $2 \mathrm{hr}$ ) immediately prior to harvesting for glucose uptake measurement. Control cultures were included which were not treated with TPA. Cells were suspended by trypsinization and incubated from $5 \mathrm{sec}$. to $20 \mathrm{~min}$. in buffer containing $\left[{ }^{3} \mathrm{H}\right] \mathrm{D}$-glucose and $\left[{ }^{14} \mathrm{C}\right]$ sucrose. Uptake was terminated with addition of a stop solution and centrifugation through an oil layer. Specific uptake was calculated after determination of radioactivity levels in the pellets. The results indicated that glucose uptake increased for up to $20 \mathrm{~min}$. incubation and that TPA stimulated glucose uptake in dog and human EC up to $300 \%$ above control values. The uptake and stimulation by TPA were greatest in primary or first passage cells and were greatly diminished in older cells. Uptake measured after 1-min. incubations was saturable with an apparent $\mathrm{KM}$ of $2.6 \mathrm{mM}$. These results indicate that glucose uptake in cultured $\mathrm{EC}$ is responsive to metabolic regulatory mechanisms and that the response to TPA is directly related to the rate of growth of the cells in culture.

(Supported in part by Miles Laboratories, Inc., New Haven, Connecticut.)
17.

Blood-brain Glucose Transport and Vascular Perfusion in Acute and Chronic Hyperglycemia

\section{J.C. LaMANNA and S.I. HARIK (Cleveland, Ohio)}

Despite the intense clinical interest in chronic hyperglycemia, little is known of its effects on the brain microcirculation. We investigated the effects of hyperglycemia, acute and chronic, on regional brain blood flow and perfusion characteristics, and on the blood-to-brain transport of glucose in awake rats. Regional cerebral blood flow and D-glucose transport were measured by the dual-label, single-pass indicator fractionation method (LaManna and Harik, Brain Res., 325: 299, 1985). D-glucose influx data were corrected by subtraction of L-glucose influx under identical conditions. Three groups of hyperglycemic rats were used. In one group, acute hyperglycemia was induced by the i.p. injection of $2 \mathrm{ml}$ of $50 \%$ glucose solution, about $20 \mathrm{~min}$. before the experimental measurements. In the other two groups, chronic hyperglycemia was induced for two or 4-5 weeks by a single i.p. injection of streptozotocin $(60 \mathrm{mg} / \mathrm{kg})$. A fourth group of rats were left untreated and served as a normoglycemic control group. Contrary to previous suggestions, we could find no decline in maximum glucose transport capacity after two or 4-5 weeks of chronic hyperglycemia. However, we found a marked decrease in the L-glucose space with chronic hyperglycemia, coupled with a moderate decrease in regional blood flow. Thus, we find that (1) both acute and chronic hyperglycemia are associated with a generalized decrease in brain blood flow, (2) chronic, but not acute, hyperglycemia is associated with a marked decrease in regional brain L-glucose space and L-glucose influx, and (3) chronic hyperglycemia has no significant effect on blood-to-brain glucose transport. Taken together, these results suggest a major decrease in the proportion of perfused brain capillaries in chronic hyperglycemia.

\section{8.}

Kinetic Analysis of the Human Blood-Brain Barrier - Evidence for an Amino Acid Pump

O.B. PAULSON, G.M. KNUDSEN, M.M. HERTZ, K.D. PETTIGREW and C.S. PATLAK (Copenhagen, Denmark; Bethesda, Maryland)

Investigations using the indicator dilution method have shown an early back diffusion of large neutral amino acids from the brain to the blood. This is not the case for, e.g., glucose. The observation is here analyzed by means of two mathematical models.

In the indicator dilution method a rapid intracarotid injection is made of a bolus containing the test substance ${ }^{14} \mathrm{C}$ - or ${ }^{3} \mathrm{H}$-labelled amino acids and the intravascular reference substances ${ }^{24} \mathrm{Na}^{+},{ }^{113 \mathrm{~m}} \mathrm{In}$-DPTA and ${ }^{36} \mathrm{Cl}^{-}$. Simultaneously, a continuous series of internal jugular venous blood samples are collected in one second time intervals to determinate the venous outflow curves. The back-diffusion of amino acids is represented as an early cross-over of the reference and test substances on the tail of the venous outflow curves. The first mathematical model takes into account the double membrane nature of the cerebral endothelial cell whereas the second takes into account for restricted passage back from the cerebral extracellular to the blood. The constants for BBB passage in each model are calculated by means of curve fitting programs.

The back-diffusion (cross-over) of the large neutral amino acids might be due to a higher permeability into the endothelial cell than out of it. Alternatively, it might be due to a higher permeability from the brain extracellular space to the blood than vice versa. The combination of the two models does not change these qualitative aspects.

Based on these results it is concluded that the transport must take place against a concentration gradient. Therefore, either large neutral amino acids are pumped into the endothelial cells or are pumped out of 
the brain from the extracellular space. In a dialysis probe study (Hutson, 1985) the content of large neutral amino acids in brain extracellular fluid has been found in the order of $1 \%$ of plasma values. This further supports the concept of active transport.

19.

\section{Accumulation of ${ }^{3} \mathbf{H}$-choline in Cerebral Endothelium}

E. HAMEL, L. EDVINSSON and E.T. MacKENZIE (Bagneux, France; Lund, Sweden)

The integrity of the cerebral endothelium is essential for the vasodilatory action of acetylcholine (ACh). Putatively, ACh diffuses through the entire thickness of the tunica media to interact with endothelial receptors, the activation of which releases a vasodilatory substance, the endotheliumderived relaxing factor (EDRF). However, in small vessels, it has been suggested that $\mathrm{ACh}$ could be synthesized, stored and released locally by the endothelial cells. In the present study we assessed the contribution of the endothelium in the supply of the vasoactive $\mathrm{ACh}$ to rabbit cerebral arteries and small pial vessels.

The endothelium was removed by an intra-aortic perfusion of a solution containing $0.1 \%$ Triton X-100. Silver nitrate staining of longitudinally-opened vessel segments revealed the complete removal of the endothelium. On transected arteries and arterioles, the endothelial cell layer was missing while other layers appeared undamaged. Denuded segments of basilar arteries did not dilate in response to $\mathrm{ACh}$ (less than $2 \%$ of the induced tone, as compared to $98 \%$ in control arteries) whereas calcitonin gene related peptide elicited a comparable vasodilatory response in control and denuded preparations ( $74 \%$ and $69 \%$, respectively). Endothelial removal drastically reduced $(53 \%$, $\mathrm{p}<0.001$ ) the amount of ${ }^{3} \mathrm{H}$-choline taken up by the cerebral arteries and small pial vessels. In contrast, the synthesizing enzyme for $\mathrm{ACh}$ and the amount of newly synthesized ${ }^{3} \mathrm{H}-\mathrm{ACh}$ released by depolarization were unaffected by denudation.

These results suggest that the endothelial cells can accumulate ${ }^{3} \mathrm{H}$-choline at low concentration but that little, if any, of the choline is metabolized into $\mathrm{ACh}$. Thus, it seems that the cerebral endothelium is not the origin of vasoactive $\mathrm{ACh}$ in major cerebral arteries and small pial vessels.

\section{0.}

Choline Uptake in Brain Capillaries May Explain Non Specific Effects of the Cholinotoxin AF64A.

\section{ESTRADA, E. GALEA and P. GOMEZ-RAMOS (Madrid, Spain)}

The choline analog ethylcholine mustard aziridinium ion (AF64A) is a potent and irreversible inhibitor of the high affinity choline transport system (HAChT) in brain synaptosomes. Intracerebral injections of this drug have been reported to selectively inhibit certain cholinergic parameters (ChAT, Ach). Therefore, AF64A has been proposed as a useful tool to inhibit cholinergic function in vivo. However, extensive morphological damage has been described in some cases following AF64A administration, suggesting a nonspecific toxic effect of the drug. Since choline is transported from blood to brain through endothelial cells, the possibility exists that AF64A would also damage the capillary endothelial cells by interacting with their choline transport system. This possibility has been tested in the present work using morphological and functional approaches.

Intraocular injections of AF $64 \mathrm{~A}$ were performed in rats. The injected retinas showed swollen light cells in the ganglion cell layer and in the innermost part of the inner nuclear layer, where cholinergic cells have been localized by immunohistochemical methods. Also necrotic areas and other lesions non related to cholinergic elements were visualized. In addition, the blood vessels of treated retinas showed contracted profiles, and the endothelial cells were dark and protruded in the lumen of the vessels. The vascular alterations were already present two hours after the injections and, in some cases, persisted for at least one week.

Isolated brain capillaries were also tested for their ability to incorporate ${ }^{3} \mathrm{H}$-choline. HAChT detected in bovine cerebral cortex capillaries was energy and sodium dependent and was inhibited by hemicholinium-3. AF64A also inhibited ${ }^{3} \mathrm{H}$-choline uptake in a concentration dependent manner.

The endothelial lesions produced after AF64A injections and the existence of a choline uptake that is inhibited by this drug in endothelial cells suggest that the presence of a HAChT in central nervous system capillaries may contribute to the apparently nonspecific lesions observed in brain and in retina after injection of the putative cholinergic toxin AF64A.

21.

Oxidation of MPTP and Several Analogues by Monoamine Oxidase of Rat Brain Microvessels

N.J. RIACHI, R.N. KALARIA, M.J. MITCHELL, L.M. SAYRE and S.I. HARIK (Cleveland, Ohio)

We recently demonstrated that rat brain microvessels are the richest source of tissue monoamine oxidase (MAO) activity, and have hypothesized that the rat's resistance to systemic MPTP neurotoxicity may be, at least in part, due to the enzymatic inactivation of the toxin at the blood-brain barrier. It is known that MPTP is a good substrate for MAO-B with a Vmax which is $\sim 60 \%$ of that of benzylamine, a known MAO-B substrate. We now report on the suitability of a number of structural analogues of MPTP as substrates for MAO of rat brain microvessels. Some of these structural analogues, particularly the fluoro-analogues could potentially be used as positron-emitting compounds for in vivo studies of subhuman primates. MAO enzymatic activity was assayed by the colorimetric determination of the $\mathrm{H}_{2} \mathrm{O}_{2}$ formed. Blanks consisted of parallel incubations in the presence of $0.1 \mathrm{mM}$ pargyline. In all of our experiments, $V \max$ and $\mathrm{Km}$ values were obtained using Lineweaver-Burk analyses.

Of all the analogues tested, only 3,3-dimethyl-MPTP had a slightly higher $V_{\max }$ than MPTP. The Vmax of MPTP oxidation was $\sim 165$ $\mathrm{nmol} / \mathrm{mg}$ protein/hour, and the $\mathrm{Km} \sim 70 \mu \mathrm{M}$. Meta-fluoro-MPTP and para-fluoro-MPTP had a V max which amounted to about $75 \%$ and $25 \%$ of that of MPTP with a similar $\mathrm{Km}$. Other analogues of MPTP which include: 2,2-dimethyl-MPTP, hydroxy-MPTP, para-methyoxy-MPTP, and pyridinium-MPTP, as well as MPP ${ }^{+}$, which is the eventual metabolite of MPTP, all gave less than $5 \%$ of the reaction of MPTP and were considered essentially nonreactive. These results suggest that metafluoro-MPTP can be oxidized by MAO and the ${ }^{18} \mathrm{~F}$-labelled compound. which is a positron emitter, may be useful in studies of the neurobiology of MPTP toxicity.

22.

Transcytosis of Blood-Borne Protein through the Intact Blood-Brain Barrier

R.D. BROADWELL, B.J. BALIN and M. SALOMAN (Baltimore, Maryland)

Potential for the transcytosis of blood-borne and CSF-borne, exogenous protein (e.g., native HRP, wheat germ agglutinin-HRP) through the non-manipulated blood-brain barrier by way of transendothelial vesicular transport and/or transendothelial tubular profiles was investi- 
gated in mouse and rat. The tracer proteins were delivered intravenously or into the lateral cerebral ventricle. Post-injection survival times were 5 mins.-24 hrs. WGA-HRP binds to specific oligosaccharides on the plasmalemma and enters cells by adsorptive endocytosis; native HRP does not bind to membrane and enters cells passively by fluid phase endocytosis. Both CSF-borne tracers were not endocytosed at the abluminal face of the cerebral endothelium; serial thin sections revealed that presumptive, peroxidase-positive endocytic vesicles within the endothelia were not vesicles but rather pits or invaginations of the abluminal surface plasmalemma. Conversely, the two blood-borne tracers were endocytosed appreciably at the luminal face of the cerebral endothelium and appeared within endocytic vesicles, endosomes, multivesicular and dense bodies, and tubules. Profiles of the latter organelle were oriented parallel or obliquely to the endothelial cell surfaces. Serial thin section analysis and application of a goniometer tilt stage consistently failed to disclose membrane continuities between the tubular profiles and the luminal and abluminal plasmalemmae. The tubules most likely represent components of the endosome apparatus (prelysosomal compartment) or lysosomal system which expresses acid hydrolase activity cytochemically. Unlike native HRP, bloodborne WGA-HRP also labeled the transmost saccule of the Golgi complex wherein the protein was packaged for export. In time, the packaged tracer was conveyed to the abluminal side of the cerebral endothelium where it was exocytosed into the perivascular clefts for eventual phagocytosis by pericytes. The data suggest that the cerebral endothelium expresses a polarity regarding the internalization of its cell surface membrane and that the transcytosis of a lectin such as WGAHRP can occur from blood to brain. Investigations of the potential transcytosis of blood-borne insulin and transferrin through the bloodbrain barrier and identification of the intracellular pathways associated with these peptides are in progress.

\section{3.}

Ultrastructural Studies of the Uptake and Transport of Homologous Albumin by Brain Endothelia

A.W. VORBRODT, A.S. LOSSINSKY and H.M. WISNIEWSKI (Staten Island, New York)

Cellular mechanisms involved in adsorption, uptake and eventual transport of homologous albumin through various types of endothelia were investigated. Micro-blood vessels (MBVs) of the mouse cerebral cortex, choroid plexus, skeletal muscle and liver sinusoids were examined after in situ vascular perfusion with a solution of mouse albumingold (AG) complex.

MBVs of cerebral cortex of adult animals, representing the bloodbrain barrier (BBB) were compared to: (a) cold injured area of brain and to (b) brains of newborn mice.

In BBB-type MBVs of adult, untreated mice, essentially no uptake of $A G$ was observed, whereas in the area of cold injury, the extravasation of AG occurs through injured ECs; in adjacent areas, the increased adsorption and uptake of $A G$ particles by numerous plasmalemmal vesicles (PVs) take place. Similar pictures were also observed in cortical MBVs of newborn animals which are characterized by greater number of PVs than in adult mice.

Choroid plexus fenestrae are not permeable to $A G$, and the tracer is transported mainly by PVs. In skeletal muscle MBVs, the tracer is taken up and transported mainly by uncoated pits and PVs. In liver sinusoids endocytosis and transport of AG particles occur rapidly (5-10 minutes) mainly through coated pits and vesicles, channel-like transfer tubules and pores (fenestrae).

Some attempts were also made to study cellular mechanisms involved in resorption of extravasated tracer, present in extracellular space of the brain.

If albumin in some organs is transported by receptor-mediated mech- anism (Ghitescu et al. J. Cell Biol. 102:1304, 1986), these receptors are probably absent from brain MBVs.

Supported in part by NINCDS grant No. NS-17271-06.

\section{4.}

Brain Endothelial Cell Gateways for Macromolecular and Inflammatory Cell Transport

\section{A.S. LOSSINSKY and H.M. WISNIEWSKI (Staten Island, New York)}

The purpose of the present study is to further investigate endothelial cell (EC) vesiculo-canalicular transport in several models of brain injury, development and aging. For nearly two decades, besides vesicular transport, tubular structures have been observed ultrastructurally by transmission electron microcopy (TEM) employing horseradish peroxidase (HRP) in numerous models of brain injury, in non-mammalian brain, and more recently in developing and aging mammalian brains suggesting a canalicular mechanism of macromolecular transport.

The present study offers further support for a brain EC channel hypothesis by comparing existing knowledge of canalicular transport and our own TEM experimental murine models to several scanning electron microscopic (SEM) studies from the literature of inflammatory cell migration across the injured BBB. Results indicate that in brain regions where the $\mathrm{BBB}$ is compromised in the mouse as demonstrated by HRP-laden vesiculo-canalicular profiles, cationized ferritin does not label their inner delimiting membranes suggesting a loss of negative electrostatic charge of these internal membrane structures. Because SEM studies have shown inflammatory cells inserting fine finger-like projections into EC membrane openings corresponding to known parajunctional membrane pores presumably in the early phase of their trans-EC migration, we propose that $\mathrm{EC}$ invaginating pits, vesicles and channel-like profiles represent gateways for macromolecules and inflammatory cells, mechanisms through which their entrance and eventual passage occur.

Supported in part by a grant from the NINCDS No. 18079.

\section{5.}

\section{How Tight are Tight Junctions in Cerebral Endothelium?}

\section{J. CERVÓS-NAVARRO (Berlin, West Germany)}

Twenty-two adult mongrel cats of $1.8-4.2 \mathrm{~kg}$ anaesthetized with 0.15 $\mathrm{ml} / \mathrm{kg}$ xylazine-hydrochloride and $25 \mathrm{mg} / \mathrm{kg}$ pentobarbital-sodium were orotracheally intubated and subjected to controlled respiration. EM examination revealed widening of the interendothelial cleft between the tight junctions. At low doses the phenomenon was discrete, however, if water loading exceeded $10 \%$ of body weight, interendothelial widening which appeared as bubbles or blisters became easily demonstrable, reaching several microns. The blisters and dehiscences were most pronounced in the corpus callosum and occipital regions. Following i.v. injection of horseradish peroxidase, the interendothelial dehiscences and blisters were completely devoid of the marker substance. Ionic lanthanum $\left(\mathrm{LA}^{3+}\right)$, however, penetrated these tight junctions. These findings indicate that by changing the osmotic gradient the tight junctions may constitute part of a paracellular pathway for the transendothelial movement of small solutes, but prevent movement of large molecules. This mechanism explains the changes in the so-called cytotoxic edema where water and ions but not proteins penetrate in the brain tissue. 
26.

Endothelial Transport of Choline Analog Measured by Positron Emission Tomography (PET)

C. REDIES, M. DIKSIC, B. COLLIER, A. GJEDDE, C.J. THOMPSON, S. GAUTHIER and W.H. FEINDEL (Montreal, Quebec)

The unidirectional transport of a choline analog across the bloodbrain barrier (BBB) and the capillary endothelium of extracranial vessels was measured in three dogs by PET. 11-C labeled pyrrolidinocholine was used as a tracer (Diksic and Jolly, J. Label. Compds. Radiopharm. 13:987, 1986).

PET data and arterial plasma samples were obtained at a fast rate for the first $90 \mathrm{~s}$ after tracer injection. Data were analysed by plotting the apparent distribution volume of tracer as a function of exposure time to tracer (Gjedde, J. Neurochem. 36: 1463, 1981). For $90 \mathrm{~s}$ after injection, uptake of tracer in brain and extracranial vessel tissue was found to be unidirectional. For brain tissue, the initial volume of distribution $V_{o}$ of pyrrolidinocholine was $0.08 \mathrm{ml} / \mathrm{g} \pm 0.03 \mathrm{SD}$. The clearence $\mathrm{K}_{\text {in }}$ was $0.017 \mathrm{ml} / \mathrm{g} / \mathrm{min} \pm 0.008 \mathrm{SD}$; assuming a brain plasma flow of 0.3 $\mathrm{ml} / \mathrm{g} / \mathrm{min}$, this yields a brain pyrrolidinocholine extraction of $6 \%$. This value is at least five times higher than the value expected from simple diffusion of tracer across the BBB (Cornford et al., J. Neurochem. $30: 299,1978$ ). For the carotid artery, $K_{\text {in }}$ was $0.07 \pm 0.05 \mathrm{ml} / \mathrm{g} / \mathrm{min}$, and, for the jugular vein, $0.11 \pm 0.09 \mathrm{ml} / \mathrm{g} / \mathrm{min}$. Therefore, the endothelium of the capillaries perfusing the walls of major blood vessels is more permeable to tracer than the BBB.

This study is the first to measure transport of a choline analog across the blood-brain barrier in vivo by PET. Such measurements may shed light on the availability of blood choline to brain and other tissues in degenerative diseases and aging of man.

Supported by MRC Grant SP-5, and DFG (Re 616/1-1).

27.

Localisation of Calcium-Activated Adenosine Triphosphatase in Cerebral Endothelium

\section{S. NAG (Kingston, Ontario)}

The plasma membrane calcium-activated adenosine triphosphatase $\left(\mathrm{Ca}^{2+}\right.$-ATPase $)$ is known to regulate intracellular calcium levels. This ultrastructural study was undertaken to determine the distribution of $\mathrm{CA}^{2+}$-ATPase in cerebral endothelium of normotensive rats and of arterioles permeable to horseradish peroxidase (HRP) of rats with angiotensin-induced acute hypertension.

Wistar-Furth rats were injected with HRP intravenously and acute hypertension was induced by a 2-minute infusion of angiotensin amide. Following perfusion of fixative, brains were sliced and reacted for demonstration of $\mathrm{HRP}$ reaction product and $\mathrm{Ca}^{2+}$ - ATPase localisation using the method of Ando et al. (1981).

There was discontinuous distribution of $\mathrm{Ca}^{2+}$-ATPase along the outer plasma membranes of endothelial, smooth muscle and adventitial cells of normotensive controls receiving saline. Reaction product was also observed in pinocytotic vesicles whether invaginating or intracytoplasmic.

Focal cortical areas of hypertensive animals showed increased arteriolar permeability to HRP. $\mathrm{Ca}^{2+}$-ATPase on the endothelial plasma membrane of permeable arterioles was reduced as compared with the nonpermeable arterioles of the same animals and controls. Permeable arterioles showed increased numbers of endothelial pinocytotic vesicles most of which contained $\mathrm{Ca}^{2+}$-ATPase. This altered $\mathrm{Ca}^{2+}$-ATPase localisation in endothelium in acute hypertension suggests that calcium may play a role in increased cerebrovascular permeability.

(Supported by Heart and Stroke Foundation of Ontario, Grant 2-6)
28.

Dexamethasone Effects on Albumin Distribution and Tumour-Associated Brain Edema

R.G. BLASBERG, H. NAKAGAWA, D.R. GROOTHUIS and C.S. PATLAK (Bethesda, Maryland; Evanston, Illinois)

The effects of dexamethasone (dex) on the distribution of albumin (1251-HSA) in RG-2 tumours and adjacent brain was studied at 1, 30 and 240 min; plasma levels of HSA were maintained constant by iv infusion and quantitative autoradiography was used to measure local tissue radioactivity. Dex treatment $(1.5 \mathrm{mg} / \mathrm{kg} \mathrm{q} 12 \mathrm{hrs} \times 5$ doses) reduced the distribution space of $\mathrm{HSA}$ in all tumour regions $[0.15 \pm$ 0.04 (SD) to $0.08 \pm 0.01 \mathrm{ml} / \mathrm{g}$ for whole tumour]. The regional influx constants for HSA in tumour were consistently but not significantly lower in dex treated animals compared to controls $[0.83 \pm 0.22$ (SE) compared to $2.4 \pm 0.9 \mu \mathrm{l} / \mathrm{g} / \mathrm{min}$ for whole tumour]. A comparison of the whole tumour influx constants and the aqueous diffusion constants of two different size tracer molecules (HSA and aminoisobutyric acid) in control animals suggests that the 'pores' across RG-2 capillaries are large and do not restrict free diffusion of HSA across the capillaries (minimum pore diameter $>36 \mathrm{~nm}$ ) and that the total pore area of the vessels is approx. $6.5 \mathrm{~cm}^{2} / \mathrm{g}$ in RG-2 tumour tissue. Analysis of the HSA concentration profiles in peripheral tumour and adjacent brain of control animals indicates that a small influx and bulk flow of plasmaderived edema fluid $(\sim 0.8 \mu \mathrm{l} / \mathrm{g} / \mathrm{min})$ occurs in addition to the diffusion of HSA through a tortuous extracellular space (ECS). Dex treatment essentially eliminated the bulk flow of plasma-derived edema fluid into the tumour and through the ECS of both tumour and adjacent brain tissue. These effects may be mediated in part by a significant reduction of the ECS (as measured by the HSA distribution space) and an increase in resistance to bulk fluid flow through a smaller ECS. This could represent an important mechanism for corticosteroid control of tumoural and peritumoural brain edema.

29.

Pharmacological Modification of Bradykinin Induced Breakdown of the Blood-Brain Barrier

D.M. ROBERTSON, J.J. RAYMOND and H.B. DINSDALE (Kingston, Ontario)

Internal carotid artery infusion of bradykinin caused extensive breakdown of the blood-brain barrier to protein as demonstrated by the extravasation of the marker, horseradish peroxidase, into vessel walls and the adjacent parenchyma. Pretreatment of the animals with indomethacin, trifluoperazine, or imidazole significantly reduced the quantity of abnormally permeable vessels as determined by light microscopy. By electron microscopy, it was determined that bradykinin caused an intense increase in the number of pinocytotic vesicles in the permeable segments, but no change in the interendothelial junctions. After imidazole pretreatment, although the extent of the permeability change was markedly reduced, the intensity of pinocytotic activity in the involved areas was not altered.

30.

Endothelial Damage Induces Local Platelet Aggregation in Pial Arterioles and Venules Without Exposing Subendothelial Structures

\section{W.1. ROSENBLUM and J. POVLISHOCK (Richmond, Virginia)}

Platelet aggregates will not form on the luminal surface of large blood vessels unless the endothelium is denuded. In contrast, in microvessels 
including pial surface arterioles and venules, denudation is not required. This is shown in two separate in vivo models using mice and cats. Model one injures endothelium by exposing vessels in situ to light from a mercury lamp in the presence of intravascular sodium fluorescein. Model two uses a much smaller spot of light (18-36 microns diameter) from a $\mathrm{HeNe}$ laser in the presence of intravascular Evans blue. In both cases adherent platelet aggregates are recognized by intravital microscopy. They adhere only to the vessels exposed to the noxious stimulus. Ultra-structural examination shows that the initial endothelial injury is characterized only by cytoplasmic lucencies, vacuoles and/or dilated smooth and rough $\mathrm{ER}$. In the $\mathrm{Hg}$ light model these minor changes clearly precede aggregation. In neither model are RBC injured, nor is there evidence of direct injury to platelets by the noxious stimuli. Many discoid platelets partake in the aggregate, along with clearly degranulating and activated platelets. Disintegration of endothelial cells and ultimate exposure of basal lamina is a later occurrence occurring minutes after aggregation has been initiated. Similar findings have been made in other microvascular beds. This suggests the need to reevaluate classical concepts concerning the relationship of an intact endothelium to local platelet aggregation.

\section{1.}

Role of Endothelium in the Constriction of Pial Vessels During Cervical Sympathetic Stimulation

T. AMANO, F. GOTOH, Y. FUKUUCHI, A. KOTO, K. TANAKA, N. SUZUKI, D. UEMATSU, J. KAWAMURA, T. YAMAWAKI, N. ITOH and K. OBARA (Tokyo, Japan)

The direct evidence for physiological role of endothelium in cerebrovascular reactivity has rarely been demonstrated in vivo. Recently, we have shown that the exposure of pial vessels to ultraviolet (UV) rays produces the selective endothelial damage of the vessels in vivo (Gotoh et al, 1985). The present study was undertaken to examine the effect of endothelial damage on the constrictive response of feline pial vessels to the stimulation of superior cervical ganglion (SCG).

Methods: Seven cats of either sex weighing 2.2-3.6 kg were anesthetized with alpha-chloralose $(50 \mathrm{mg} / \mathrm{kg}$ i.p. $)$ and urethane $(500 \mathrm{mg} / \mathrm{kg}$ i.p. $)$ followed by artificial respiration. A cranial window made of quartz and stainless steel frame was screwed into the parietal region of the skull. Changes in the diameter of pial vessels were continuously recorded by means of a video camera system. Ipsilateral SCG to the cranial window was stimulated with square-wave impulse of $2-m s$ duration at $15 \mathrm{~Hz}$ and $5 \mathrm{~V}$ for $3 \mathrm{~min}$ before and after irradiation of the brain surface with UV rays.

Results: Before the UV irradiation, the pial arteries (resting diameter $120.2 \pm 20.7 \mu)$ constricted significantly by $10.6 \pm 2.2 \%(\mathrm{p}<0.05)$ and $10.3 \pm 2.4 \%(p<0.005)$ at $2 \mathrm{~min}$, and $3 \mathrm{~min}$ after the start of SCG stimulation, respectively. After the UV irradiation, however, the constrictive response of the pial arteries (resting diameter $148.5 \pm 23.7 \mu$ ) to the stimulation was inhibited, and the extent of constriction was only $0.1 \pm 0.7 \%$ and $0.2 \pm 0.7 \%$ at $2 \mathrm{~min}$ and $3 \mathrm{~min}$.

Conclusion: The endothelium plays an important role in the vasoconstrictive response of the pial vessels to cervical sympathetic stimulation.

\section{2.}

Dilatation of Pial Arteries In Vivo by Carbachol is Abolished by Endothelial Lesion Induced by Air Embolism

C. HALLER, R. SERCOMBE, C. VERRECCHIA, H. FRITSCH, W. KUSCHINSKY and J. SEYLAZ (Bonn 1, Fed. Rep. Germany; Paris, France)

Cerebral artery relaxation to muscarinic substances has been shown in vitro to depend on endothelial integrity. In the present experiments we compared, in anaesthetized cats, the in vivo reactions of cerebral arteries to a muscarinic substance before and after endothelial damage. Methods: 1. The normal reactivity of pial arteries to carbachol $\left(10^{-7}-10^{-5} \mathrm{M}\right)$ was tested, using the microapplication technique. 2. After arterial air embolism, the reactivity was re-tested in the same vessels. 3. Pial arteries were taken out and examined for morphological alterations.

Results: Phase 1: During control conditions consistent dilatations to carbachol were found. Repetitions of the test gave reproducible curves for the same vessel (no tachyphylaxis). Phase 2: After air embolism the reactions of the same vessels to carbachol were completely abolished. Phase 3: After perfusion fixation, equivalent segments of pial arteries from each hemisphere were removed and examined by scanning electron microscopy. 7 arteries from 4 control animals showed typical intact endothelium. In 21 arteries removed from 10 cats subjected to air embolism various degrees and types of endothelial alteration were observed. All arteries showed flattening of the endothelial nuclei, but 18 showed also tears, cracks or holes, and occasionally the endothelial cells were partially stripped of the elastic lamina. Frequent platelet aggregations were also observed.

Conclusions: (a) morphologically verified endothelial lesion in vivo abolishes muscarinic vasodilatation; therefore, the results of in vitro studies can be applied to in vivo conditions (b) destruction of endothelium, as performed in in vitro studies, is not a prerequisite for disturbed vascular function: moderate endothelial damage may be sufficient to affect vasomotor mechanisms in vivo.

33.

Vasodilatation and Disruption of the Blood-Brain Barrier During Acute Hypertension

W.G. MAYHAN, G.L. BAUMBACH and D.D. HEISTAD (lowa City, lowa) ${ }^{*}$

Acute hypertension produces disruption of the blood-brain barrier (BBB) primarily in venules. We have suggested that hypercapnia protects the BBB during acute hypertension. Protection of the BBB by hypercapnia may be related to an effect of acidosis on the BBB, vasodilatation during hypercapnia, or attenuation of increases in pial venous pressure (PVP) by hypercapnia. Our first goal was to determine whether protection of the BBB by hypercapnia during acute hypertension is related to acidosis. We compared disruption during hypercapnia (vasodilatation with acidosis) and adenosine (vasodilatation without acidosis). Our second goal was to determine whether protection is related to attenuation of increases in PVP. We examined disruption of the BBB during passive increases in PVP during hypercapnia.

Pial vessels were examined in rats using fluorescent microscopy. Disruption of the BBB was evaluated by counting leaky sites (LS). We produced dilatation of pial vessels by systemic hypercapnia or topical adenosine. PVP was measured during normocapnia, hypercapnia, and adenosine, during normotension and acute hypertension. Increase in PVP ( $\mathrm{mmHg}$ ) and LS in response to acute hypertension (values are mean $\pm \mathrm{SE},{ }^{*} p<0.05$ vs. normocapnia):

\begin{tabular}{|c|c|c|c|}
\hline & Normocapnia & Hypercapnia & Adenosine \\
\hline $\begin{array}{l}\triangle \text { PVP } \\
\text { LS }\end{array}$ & $\begin{array}{l}18 \pm 1 \\
19 \pm 1\end{array}$ & $\begin{array}{l}8 \pm 2^{*} \\
9 \pm 1^{*}\end{array}$ & $\begin{array}{l}18 \pm 2 \\
19 \pm 2\end{array}$ \\
\hline
\end{tabular}

In other hypercapnic rats, venous occlusion increased PVP by $18 \pm 2$ $\mathrm{mmHg}$ and LS increased from 0 to $16 \pm 2$. Thus, when PVP is similar during normocapnia and hypercapnia, susceptibility to disruption of the BBB is similar. We suggest that protection of the BBB during acute hypertension by hypercapnia 1) is not mediated by direct effects of acidosis or vasodilatation, and 2 ) is related to attentuation of increases in PVP. 
34.

Possible Influence of Cerebral Endothelium on Smooth Muscle Calcium Channels

R. SERCOMBE, C. VERRECCHIA, V. PHILIPSON, E. HAMEL and J. SEYLAZ (Paris, France; Bagneux, France)

Recently, the cerebral endothelium was demonstrated in vitro to play an important role in determining the reactivity of pial arteries to acetylcholine (ACh), noradrenaline (NA) and histamine (HA). The mechanisms of its involvement in responses to $\mathrm{ACh}$ and $\mathrm{HA}$ seem to implicate specific receptors presumed to be on the endothelium. Studies on peripheral vessels suggest that modifications of calcium flux may be involved in the altered reaction to $\mathrm{NA}$ after endothelium removal. The present series of experiments was therefore undertaken to investigate the effects of endothelium removal on vasoconstriction known to be induced via $\mathrm{Ca}^{2+}$ influx.

Segments of rabbit cerebral arteries were perfused in vitro; measurements of vascular reactivity were made after intra- or extraluminal administration of different agents. In each experiment, tests were made with ACh, HA, the calcium ionophore A23187, high $\mathrm{K}^{+}$solution, BAY K8644 $\left(\mathrm{Ca}^{2+}\right.$ channel agonist) or verapamil before and after endothelium lesioning by a brief perfusion of triton $X-100$. Examination of arteries by scanning electron microscopy showed that $30 \mathrm{sec}$. triton $X-100$ perfusion caused severe damage to the endothelium.

The endothelial lesions abolished the relaxation to ACh, HA, A23187 and significantly reduced that to verapamil, but did not affect that to papaverine. Constriction due to high $\mathrm{K}^{+}$solution or BAY K8644 was significantly diminished (by $85-90 \%$ ) even after only $10 \mathrm{sec}$. triton perfusion, whereas $30 \mathrm{sec}$. exposure to triton was required to attain the same reduction of the $\mathrm{ACh}$ relaxation.

These results show that (a) triton perfusion is a convenient method for endothelium lesioning, (b) there may be an endothelium-derived factor which affects $\mathrm{Ca}$ flux into vascular smooth muscle, (c) such an endothelial factor may not be the same as the relaxing factor released by activation with $\mathrm{ACh}$. Further experiments are required to elucidate how the modulation of NA responses by the endothelium is related to such properties.

35.

Blood-Brain Transport of IAP, IQNB and Cyclofoxy as Measured by Indicator Diffusion (ID) and Brain Uptake Index (BUI) Methods

Y. SAWADA, S. HIRAGA, C.S. PATLAK and R.G. BLASBERG (Bethesda, Maryland)

Cerebrovascular transport of 1311-iodoantipyrine (IAP) 1251-(R,S) quinuclidinyl benzilate (IQNB) and $3 \mathrm{H}$-cyclofoxy $(\mathrm{CF})$ was measured in lightly anesthetized Sprague-Dawley rats. The intracarotid injectate $(50 \mu l)$ included the above drugs plus a vascular reference (57Co-DTPA or 67Ga-EDTA) and $46 \mathrm{Sc}$-microspheres $(15 \mu)$ in whole blood. Torcula sinus blood was measured every sec and the animal was decapitated at $15 \mathrm{sec}$. The venous outflow data were analyzed by a 2 compartment distributed model and a BUI was calculated for several brain areas; unidirectional permeability-surface area products (PS) were determined from both sets of data. The ID method gave higher values of PS for IAP than the BUI method; whereas, similar values were obtained by both methods of IQNB and CF. The rank order of PS was IAP $>C F>I Q N B$ for both methods, while the rank order of the octanol/buffered saline partition coefficient was IQNB $>I A P>C F$. These results indicate that the binding of lipid soluble drugs to blood constituents (IQNB $>$ IAP $>C F$ ) is an important determinant of the unidirectional transport across the blood-brain barrier.

\begin{tabular}{|c|c|c|c|c|c|}
\hline \multicolumn{6}{|c|}{ Unidirectional Transport Parameters } \\
\hline Ligand & $\mathrm{PC}^{\dagger}$ & futt & $\mathrm{Cp} / \mathrm{Cb} \ddagger$ & PS*(ID) & PS*(BUI) \\
\hline IAP & 15 & 0.51 & 0.995 & $5.43 \pm .93$ & $1.80 \pm .49$ \\
\hline R-IQNB & 65 & 0.086 & 1.44 & $0.82 \pm .11$ & $0.42 \pm .03$ \\
\hline S-IQNB & 65 & 0.092 & 1.58 & $0.51 \pm .06$ & $0.51 \pm .08$ \\
\hline $\mathrm{CF}$ & 6 & 0.90 & 0.74 & $1.28 \pm .08$ & $0.84 \pm .06$ \\
\hline
\end{tabular}

$\dagger$ octanol/saline partition coefficent

$\dagger \dagger$ unbound fraction in plasma ( $\mathrm{fu}$ )

¥ plasma/blood concentration ratio

* units: $\mathrm{ml} / \mathrm{g} / \mathrm{min}$; $\pm \mathrm{SEM}$

36.

Role of Arginine Vasopressin in Regulation of Cerebral Circulation

F.M. FARACI, P.G. SCHMID and D.D. HEISTAD (lowa City, lowa)

The goal of this study was to examine effects of vasopressin on cerebral blood vessels. We measured cerebral blood flow (microspheres) and pressure (servo null) in pial arteries ( $180 \mu \mathrm{m}$ diameter) in anesthetized cats, and calculated resistance of large and small cerebral vessels. Intravenous infusion of vasopressin raised plasma levels from $5.5 \pm 1.2$ $(\mu \mathrm{U} / \mathrm{ml})$ to $343 \pm 69$ (mean \pm SE). Resistance of large arteries $(>180$ $\mu \mathrm{m})$ was approximately $50 \%$ of total resistance under control conditions. Vasopressin decreased resistance of large arteries by $22 \pm 7 \%$, increased pial artery pressure by $10 \pm 2 \mathrm{mmHg}$ (with no change in aortic pressure), and increased small vessel resistance by $27 \pm 11 \%$. Cerebral blood flow was not changed ( $38 \pm 4 \mathrm{vs} .37 \pm 3 \mathrm{ml} / \mathrm{min} \times 100 \mathrm{~g}$ ). In a second group of animals, we examined the mechanism of small vessel constriction during vasopressin infusion. When pial artery pressure was maintained constant during vasopressin infusion, resistance of small vessels was unchanged. Thus, constriction of small vessels during infusion of vasopressin was an autoregulatory response to increases in pial artery pressure and not a direct effect of vasopressin. We also superfused vasopressin $\left(10^{-9}\right.$ to $\left.10^{-7} \mathrm{M}\right)$ on pial vessels and observed dose-dependent dilatation of large $(169 \pm 4 \mu \mathrm{m})$ and small $(73 \pm 6 \mu \mathrm{m})$ pial arteries. At the high dose, large and small pial arteries dilated by $32 \pm 4 \%$ and $42 \pm 5 \%$, respectively. Thus, 1) perivascular vasopressin is a dilator of pial arteries, and 2) circulating vasopressin, at levels similar to those observed during shock or after sudden hemorrhage, selectively dilates large cerebral arteries, increasing microvascular pressure without changing cerebral blood flow. We speculate that vasopressin may play an important role in regulation of cerebral microvascular pressure.

37.

A Model for Application of the Indicator Dilution Method in the Brain with Intravenous Injection

O.B. PAULSON, G.M. KNUDSEN, M.M. HERTZ, K.D. PETTIGREW and C.S. PATLAK (Copenhagen, Denmark; Bethesda, Maryland)

The indicator dilution method has been used for evaluation of the vascular permeability of the blood-brain barrier in humans. Classically, an intracarotid bolus injection of isotopically labeled test substance and impermeable reference substance is given, followed immediately by blood sampling from the internal jugular vein. The requirement of puncturing the carotid artery is the major limitation of this technique. The present study introduces a modification of the former technique. using intravenous instead of intracarotid injection.

After intravenous injection, the arterial concentrations of the isotopes, measured in a peripheral artery, rise within 10-15 sec., reaching peak values at about $20 \mathrm{sec}$. and, finally, declining to approximately steady values for at least $10 \mathrm{sec}$. Due to the different uptakes in the lungs the individual arterial concentrations of the isotopes will differ, leading to 
different inputs to the brain. That is, the arterial reference and test curves are no longer identical as they were when using the carotid injection technique. Thus, with intravenous injection it is necessary to determine a pseudo reference output curve which would have been the output of the reference substance if its input to the brain had been the same as the test substance input. This is accomplished by finding the transfer function for the reference material through the cerebral vascular bed and applying this function to the arterial test curve. This resultant curve can then be used as the reference curve in determining the parameters of the system.

Certain advantages are obtained by the introduction of the intravenous method; recirculation is taken into account and longer collection periods are possible. The approach for estimating transfer constants across the blood-brain barrier is now similar to those used in the intracarotid method.

\section{8.}

Size-dependent Blood-Brain Barrier Opening Demonstrated with 14Csucrose and a 200,000 Dalton 3H-Dextran

\section{S.I. RAPOPORT, B.K. ARMSTRONG and P.J. ROBINSON (Bethesda, Maryland)}

Reclosure of the blood-brain barrier (BBB) following osmotic opening was investigated by determining capillary permeability-surface area products (PA) of two neutral water soluble radiotracers of widely differing size. 14C-sucrose ( $\mathrm{MW} 340$ dalton, $r=5 \mathrm{~A}$ ) and $3 \mathrm{H}$-dextran (MW 200,000 daltons, $r=100 A$ ) were injected simultaneously i.v. into awake rats, between 1 and $50 \mathrm{~min}$ after a $30 \mathrm{~s}$ infusion of $1.8 \mathrm{~m}$ $\mathrm{L}(+)$-arabinose into the right external carotid artery. Regional PA's were determined by the intravenous bolus method of Ohno et al. (1978), over 5 min periods of tracer circulation. Control PA equaled $10-5 \mathrm{~s}-1$ for sucrose and was negligible for dextran. PA increased to $4 \times 10-4 \mathrm{~s}-1$ and 10-4 s-1 for sucrose and dextran, respectively, at 6 min after BBB opening, and then declined for both tracers. The ratios of PA (sucrose) to PA (dextran) were consistent with restricted diffusion through pores or slits at 35 and $55 \mathrm{~min}$ after BBB opening, but were less than the corresponding free-diffusion ratios at 6 and $10 \mathrm{~min}$, indicative of bulk flow with solute drag from blood to brain. The measured increment in brain water after BBB opening, and the present results, suggest the creation of slits approximately 400 A wide by osmotic treatment. Reduction in bulk fluid flow with time appears to be the major cause for the reduced PA's of sucrose and dextran during recovery of $\mathrm{BBB}$ integrity after the osmotic insult. The results are consistent with a tight junctional but not a pinocytotic model for osmotically-induced $\mathrm{BBB}$ opening.

\section{9.}

\section{Regulation of Blood Flow to Choroid Plexus}

F.M. FARACI, W.G. MAYHAN and J.K. WILLIAMS (Iowa City, lowa)

Regions of the brain such as the choroid plexus and other circumventricularorgans lack capillaries with tight endothelial junctions. Regulation of blood flow may differ in choroid plexus compared with regions such as the cerebrum which has tight endothelial junctions (a bloodbrain barrier). The goal of this study was to examine effects of intravascular dilators and constrictors on blood flow to the choroid plexus. In anesthetized rabbits and dogs, blood flow to choroid plexus was measured with microspheres under control (CON) conditions, during intraveneous adenosine $(5 \mu \mathrm{M} / \mathrm{kg} / \mathrm{min})(A D E N)$, and during either intravenous phenylephrine $(25 \mu \mathrm{g} / \mathrm{min})$ (PE) or norepinephrine (10 $\mu \mathrm{g} / \mathrm{min}$ ) (NE). Aortic pressure (AoP) was maintained constant during phenylephrine and norepinephrine. Consecutive measurements under control conditions produced reproducible blood flow values. Values for blood flow to choroid plexus obtained by simultaneous injection of 15 and $50 \mu \mathrm{m}$ microspheres during adenosine were similar, which suggests that there was no significant shunting of $15 \mu \mathrm{m}$ microspheres. Results (blood flow in $\mathrm{ml} / \mathrm{min} \times 100 \mathrm{~g} ;{ }^{*}=\mathrm{p}<0.05 \mathrm{vs}$. control):

\begin{tabular}{lccc} 
Rabbit $(\mathrm{n}=6)$ & $\mathrm{CON}$ & ADEN & PE \\
\cline { 2 - 4 } Choroid Plexus & $442 \pm 103$ & $765 \pm 170^{*}$ & $163 \pm 36^{*}$ \\
Cerebrum & $28 \pm 3$ & $31 \pm 5$ & $31 \pm 3$ \\
AoP $(\mathrm{mmHg})$ & $71 \pm 3$ & $45 \pm 7^{*}$ & $76 \pm 9$ \\
Dog $(\mathrm{n}=8)$ & $\mathrm{CON}$ & ADEN & $\mathrm{NE}$ \\
Choroid Plexus & $310 \pm 32$ & $868 \pm 179^{*}$ & $165 \pm 29^{*}$ \\
Cerebrum & $32 \pm 3$ & $36 \pm 5$ & $37 \pm 5$ \\
AoP (mmHg) & $123 \pm 7$ & $75 \pm 8^{*}$ & $124 \pm 8$
\end{tabular}

We conclude that vasoactive agonists may have different effects on blood flow to choroid plexus and cerebrum. 